\title{
Correction to: Casein micelles from bovine Milk exerts Neuroprotection by stalling metabolic complications linked to oxidative brain injury
}

\author{
Ochuko L. Erukainure ${ }^{1}$ (D) Veronica F. Salau ${ }^{2} \cdot$ Opeyemi O. Alabi $^{3} \cdot$ Osaretin A. T. Ebuehi $^{4} \cdot$ Neil A. Koorbanally $^{5} \cdot$ \\ Md. Shahidul Islam²
}

Published online: 13 October 2020

(C) Springer Science+Business Media, LLC, part of Springer Nature 2020

Correction to: Metabolic Brain Disease (621). https://doi.org/10.1007/s11011-020-00621-3

\begin{abstract}
Author "Shahidul Islam" should be "Md. Shahidul Islam".

* The original online version of this article was revised
\end{abstract}

Publisher's note Springer Nature remains neutral with regard to jurisdictional claims in published maps and institutional affiliations.

The online version of the original article can be found at https://doi.org/ 10.1007/s11011-020-00621-3

Ochuko L. Erukainure

loreks@yahoo.co.uk

1 Department of Pharmacology, University of the Free State, Bloemfontein 9300, South Africa

2 Department of Biochemistry, University of KwaZulu-Natal, Westville Campus, Durban 4000, South Africa

3 Department of Food Technology, Federal University, Oye-Ekiti, Ekiti, Nigeria

4 Department of Biochemistry, University of Lagos, Lagos, Nigeria

5 School of Chemistry and Physics, University of KwaZulu-Natal, Westville Campus, Durban 4000, South Africa 